\title{
Promosi dan Evaluasi Penerapan Budaya Keselamatan Pasien
}

\author{
Intan Faadhilah \\ Intanfaadhilah24@gmail.com
}

\begin{abstract}
Di rumah sakit, dampak dari budaya keselamatan pasien yang kurang adalah tingginya angka Kejadian Tidak Diharapkan seperti infeksi nosokomial dan pasien jatuh, Kejadian Nyaris Celaka, ataupun kejadian sentinel. Budaya keselamatan pasien dipengaruhi oleh beberapa faktor personal, diantaranya komitmen personal, pengetahuan, dan kompetensi petugas kesehatan yang bertugas di rumah sakit. Tujuan dari pengaruh budaya terhadap keselamatan pasien dirumah sakit ini adalah apabila pasien memiliki budaya yang berbeda dengan tenaga kerja kesehatan atau perawat agar melakukan komunikasi. Metode yang digunakan adalah metode kualitatif dimana maksudnya dengan cara mengumpulkan sebanyak-banyaknya data untuk dianalisis. Yaitu dengan Literature review ini dengan menganalisis yang berfokus pada kompetensi kemampuan berpikir dalam praktik keperawatan. Adapun tinjauan literatur yang digunakan seperti buku teks, bukureferensi, jurnal, dan google scholar. Dengan kata kunci Pengaruh Budaya Keselamatan Pasien, Peningkatan Mutu Pelayanan Rumah Sakit, Peran Perawat. Dan yang digunakan adalah 14 literatur yang diterbitkan 10 tahun terakhir.
\end{abstract}

\section{Latar Belakang}

Keselamatan pasien merupakan inti dari mutu pelayanan kesehatan. Untuk mencapainya, diperlukan komitmen yang kuat dari individu maupun tim. Budaya keselamatan pasien yang baik dapat memperkecil insiden yang berhubungan dengan keselamatan pasien. Perawat yang juga berperan menjadi champion keselamatan pasien telah diterapkan diberbagai rumah sakit di Indonesia. Penerapan budaya keselamatan pasien yang adekuat akan menghasilkan pelayanan keperawatan yang bermutu. Pelayanan kesehatan yang bermutu tidak cukup dinilai dari kelengkapan teknologi, sarana prasarana yang canggih dan petuugas kesehatan yang profesional, namun juga ditinjau dari proses dan hasil pelayanan yang diberikan (Ilyas, 2004). Budaya keselamatan pasien yang baik dapat memperkecil insiden yang berhubungan dengan keselamatan pasien. Penelitian Harvard School of Public Health (HSPH) (2011) 
menyebutkan bahwa dari seluruh dunia 43 juta orang dirugikan setiap tahun akibat perawatan yang tidak aman. Sekitar $70 \%$ dari pasien yang mengalami kesalahan medis menderita cacat ringan atau sementara, $7 \%$ pasien cacat permanen dan 13,6\% kasus berakibat fatal (Collinson, Throne, Dee, MacIntyre, \& Pidgeon, 2013). Data dari National Patient Safety Agency, menyebutkan dari kurun waktu AprilSeptember 2012 di London Inggris pada pelayanan kesehatan akut spesialis terjadi insiden yang tidak diinginkan sebanyak $56.1 \%$. Perumah sakitentase insiden terumah sakitebut menimbulkan kerugian ringan sebanyak 34.3 $\%$, kerugian sedang sebanyak $21.1 \%$, kerugian berat sebanyak $0.5 \%$ dan sebanyak $0.2 \%$ berkibat fatal. Rumah sakit harus bisa memastikan penerima pelayanan kesehatan terbebas dari resiko pada proses pemberian layanan kesehatan (Cahyono, 2008; Fleming \& Wentzel, 2008). Penerapan keselamatan pasien di rumah sakit dapat mendeteksi resiko yang akan terjadi dan meminimalkan dampaknya terhadap pasien dan petugas kesehatan khususnya perawat.

\section{Metode}

Metode yang digunaka adalah metode kualitatif dimana maksudnya dengan cara mengumpulkan sebanyak-banyaknya data untuk dianalisis. Yaitu dengan Literature review ini dengan menganalisis yang berfokus pada kompetensi kemampuan berpikir dalam praktik keperawatan. Adapun tinjauan literatur yang digunakan seperti buku teks, bukureferensi, jurnal, dan google scholar. Dengan kata kunci Pengaruh Budaya Keselamatan Pasien, Peningkatan Mutu Pelayanan Rumah Sakit, Peran Perawat.Dan yang digunakan adalah 14 literatur yang diterbitkan 10 tahun terakhir.

\section{Hasil}

Semua organisasi mempunyai budaya kerja masing-masing, termasuk rumah sakit. Misal, saat masuk ke salah satu unit di rumah sakit, kita bisa segera menilai apakah petugasnya ramah, siap membantu, pelayanannya cepat, dimana hal tersebut salah satu contoh dari dimensi budaya patient safety yang bisa dirasakan. Schein (1992) mendefinisikan budaya kerja sebagai kebiasaan orang bekerja dalam suatu kelompok, nilai, filosofi dan aturanaturan dalam kelompok yang membuat mereka bisa bekerjasama. Secara singkat budaya kerja adalah bagaimana kita menyelesaikan pekerjaan ditempat kerja yang berperan penting dalam keberhasilan atau kegagalan suatu organisasi pelayanan kesehatan dan juga dalam konteks patient safety. Guldenmund (2010) mengatakan bahwa budaya keselamatan sebagai aspekaspek dari budaya organisasi yang akan mempengaruhi sikap dan perilaku terkait dengan 
peningkatan atau penurunan risiko. The International Nuclear Safety Advisory Group (INSAG), dalam publikasinya Safety Series No. 75 INSAG-4, mendefinisikan budaya keselamatan merupakan gabungan karakteristik dan sikap dalam organisasi dan individu yang menetapkan bahwa, sebagai prioritas utama masalah keselamatan instalasi nuklir memperoleh perhatian yang sesuai dengan kepentingannya. Pentingnya mengembangkan budaya patient safety juga ditekankan dalam salah satu laporan Institute of Medicine "To Err Is Human" agar organisasi tersebut berfokus pada peningkatan reliabilitas dan keselamatan pelayanan pasien". Nieva dan Sorra turut menekankan bahwa budaya keselamatan yang buruk adalah faktor risiko penting yang bisa mengancam keselamatan pasien. Kohn (2000) dalam Rosyada (2014), budaya keselamatan pasien dikembangkan dari konsep budaya keselamatan di industri. Walaupun memiliki karakteristik yang berbeda, berbagai penelitian budaya keselamatan di industri menjadi dasar pengembangan konsep keselamatan pasien di rumah sakit. Salah satu perbedaan konsepnya adalah budaya keselamatan pasien di rumah sakit lebih berfokus untuk melindungi pasien lebih besar daripada perlindungan terhadap personel itu sendiri. Menurut IOM (Intitute of Medicine), terciptanya lingkungan yang aman bagi pasien berarti tercipta juga lingkungan yang aman bagi pekerja, karena keduanya terikat satu sama lain. Dalam bukunya, Vincent (2005) menyebutkan ancaman terhadap keselamatan pasien tersebut tidak dapat diubah, jika budaya patient safety dalam organisasi tidak diubah. Di rumah sakit,salah satu dampak dari budaya keselamatan pasien yang kurang adalah tingginya angka kejadian KTD, KNC, ataupun kejadian sentinel. Salah satu bentuk dari KTD adalah infeksi nosokomial dan pasien jatuh. Model Bandura (1986) tentang determinisme timbal balik menjelaskan bahwa budaya keselamatan terdiri dari 3 aspek yang saling terkait, yaitu aspek psikologis, aspek perilaku dan aspek situasional. a. Aspek psikologis dari budaya keselamatan sering disebut sebagai "iklim keselamatan (safety climate)" atau dengan kata lain “bagaimana orang merasa tentang keselamatan dan sistem manajemen keselamatan”. Aspek ini berhubungan dengan nilai-nilai individu \& kelompok serta sikap dan persepsi terhadap keselamatan. b. Aspek perilaku budaya keselamatan memberikan perhatian pada "apa yang dilakukan orang-orang". Ini termasuk kegiatan yang terkait dengan keselamatan, perilaku, juga komitmen manajemen terhadap keselamatan. c. Aspek situasional mengacu pada apa yang organisasi punya. Ini termasuk misalnya kebijakan, prosedur, peraturan, struktur organisasi, sistem manajemen, sistem kontrol dan sistem komunikasi. 


\section{Kesimpulan}

Dalam penerapan program keselamatan pasien terdapat beberapa aspek yang mempengaruhi berjalannya program penerapan keselamatan pasien. Aspek-aspek tersebut antara Iain: iklim organisasi, tingkat pengetahuan, komunikasi, dan etika. Budaya keselamatan pasien akan tercipta apabila tenaga kesehatan memiliki pemimpin yang bersedia bekerja sama demi terlaksananya patient safety. Selain itu pengetahuan dan komunikasi juga berpengaruh terhadap ter:aksananya patient safety. Salah satu aspek yang penting dalam terlaksananya patient safety yaitu aspek etika. Etika sangatlah penting karena akan menyangkut tentang prosedur dalam melaksanakan asuhan keperawatan atau melaksanakan tugas dalam melayani kesehatan. Dalam pelayanan kesehatan maka tenag medis harus sesuai dengan kode etik dan hukum kesehatan. Hal ini untuk menghindari atau mengurangi praduga terjadinya malpraktik.

\section{Referensi}

Darliana, D. (2016). Hubungan Pengetahuan Perawat dengan Upaya Penerapan Patient Safety di Ruang Rawat Inap Rumah Sakit Umum Daerah Dr, Zainoel Abidin Banda Aceh. Idea Nursing Journal. 7 (1), 62-63.

Firawati. (2012). Pelaksanaan Program Keselamtan pasien di RSUD Solok. Jurnal Kesehatan Masyarakat. 6 (2), 74-77.

Ginting, D. (2019). Kebijakan Penunjang Medis Rumah Sakit (SNARS). Yogyakarta : Deepublish.

Haris, B., D., \& Sutriningsih, A. (2015). Pengetahuan Perawat Tentang Keselamatan Pasien dengan Pelaksanaan Prosedur Keselamatan Pasien Rumah Sakit (KPRS) di Rumah Sakit Panti Waluya Sawahan Malang. 3(1), 25-27.

Herawati, Y., T. (2015). Budaya Keselamatan Pasien di Ruang Rawat Inap Rumah Sakit X Kabupaten Jember. Jurnal Ikatan Kesehatan Masyarakat. 11(1), 54-58.

Hermanto, W. (2016). Tingkat Pengetahuan Perawat Tentang Patient Safety di Rumah Sakit Adi Husada Surabaya. Adi Husada Nursing Journal. 2(1), 68-69

Iskandar, E. (2017). Tata Kelola dan Kepatuhan Penerapan Standar Patient Safety Penyakit Stroke di Rumah Sakit Dr Kanujoso Djatiwibowo. Jurnal Administrasi Rumah Sakit. 3(3), 169-170. 
Ismainar, H. (2019). Keselamatan Pasien di Rumah Sakit. Yogyakarta : Deepublish.

Kemenkes RI. (2011). Permenkes RI No.1691/Menkes/VIII/2011 tentang Keselamatan Pasien Rumah Sakit.

Najihah. (2018). Budaya Keselamatan Pasien dan Insiden Keselamatan Pasien Di Rumah Sakit: Literature Review. Journal Of Islamic Nursing. 3 (1), 1-4.

Rivai, F., Sidin, A., I., \& Kartika, I. (2016). Faktor Yang Berhubungan Dengan Implementasi Keselamatan Pasien Di Rsud Ajjappannge Soppeng Tahun 2015. Jurnal Kebijakan Kesehatan Indonesia. 5(4), 152-154.

Simamora, R. H. (2018). Buku Ajar Keselamatan Pasien Melalui Timbang Terima Pasien Berbasis Komunikasi Efektif: SBAR.

Simamora, R. H. (2019). Buku Ajar Pelaksanaan Identifikasi Pasien. Uwais Inspirasi Indonesia.

Simamora, R. H., \& Fathi, A. (2019). The Influence of Training Handover based SBAR communication for improving Patients Safety. Indian Journal of Public Health Research \& Development, 10(9), 1280-1285.

Simamora, R, H. ( 2019) Documention Of Patient Identifikasi Into Guality Of Nursing Serviceec International Journal Of Soenrifio \& Technology tesearch.

Yasmi, Y., \& Thabrany, H. (2018). Faktor-Faktor yang Berhubungan dengan Budaya Keselamatan Pasien di Rumah Sakit Karya Bhakti Pratiwi Bogor Tahun 2015. Jurnal Administrasi Rumah Sakit. 4 (2), 99-103.

Yulidar, Girsang, E., \& Nasution, A., N. (2019). Analisis Faktor-Faktor yang Mempengaruhi Perilaku Perawat Dalam Rangka Penerapan Patient Safety di Rawat Inap Rumah Sakit Royal Prima Jambi Tahun 2018. Scientia Journal. 8 (1), 370-371.

Yusuf, M. (2017). Penerapan Patient Safety di Ruang Rawat Inap Rumah Sakit Umum Daerah Dr. Zainoel Abidin. Jurnal Ilmu Keperawatan. 5 (1), 84-85. 